
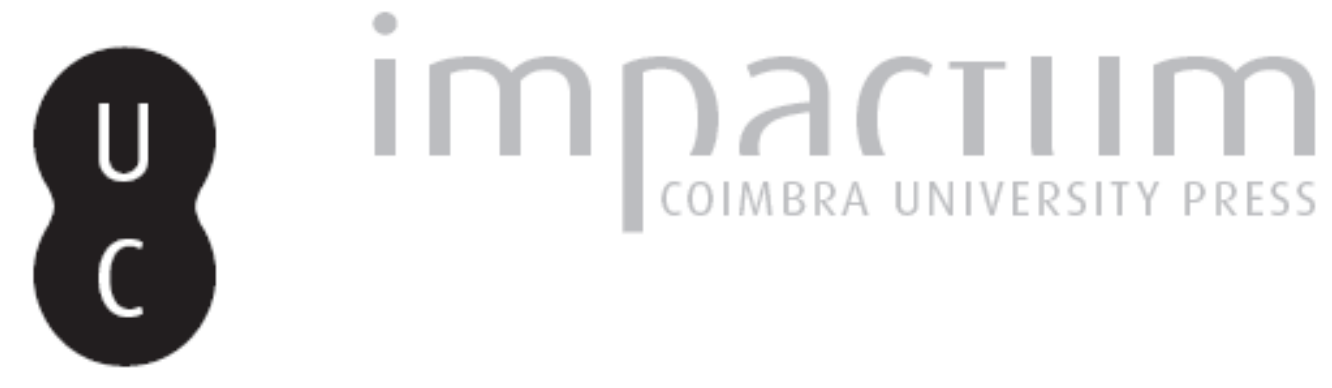

\title{
Lisboa e Lagos nos séculos XV-XVI: a comunidade italiana e a Igreja de Nossa Senhora do Loreto
}

\author{
Autor(es): $\quad$ Martins, José António \\ Publicado por: Imprensa da Universidade de Coimbra \\ URL \\ persistente: \\ URI:http://hdl.handle.net/10316.2/45638 \\ DOI: \\ DOI:https://doi.org/10.14195/0870-8584_13_5
}

Accessed : $\quad$ 26-Apr-2023 10:55:45

A navegação consulta e descarregamento dos títulos inseridos nas Bibliotecas Digitais UC Digitalis, UC Pombalina e UC Impactum, pressupõem a aceitação plena e sem reservas dos Termos e Condições de Uso destas Bibliotecas Digitais, disponíveis em https://digitalis.uc.pt/pt-pt/termos.

Conforme exposto nos referidos Termos e Condições de Uso, o descarregamento de títulos de acesso restrito requer uma licença válida de autorização devendo o utilizador aceder ao(s) documento(s) a partir de um endereço de IP da instituição detentora da supramencionada licença.

Ao utilizador é apenas permitido o descarregamento para uso pessoal, pelo que o emprego do(s) título(s) descarregado(s) para outro fim, designadamente comercial, carece de autorização do respetivo autor ou editor da obra.

Na medida em que todas as obras da UC Digitalis se encontram protegidas pelo Código do Direito de Autor e Direitos Conexos e demais legislação aplicável, toda a cópia, parcial ou total, deste documento, nos casos em que é legalmente admitida, deverá conter ou fazer-se acompanhar por este aviso.

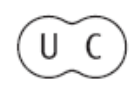




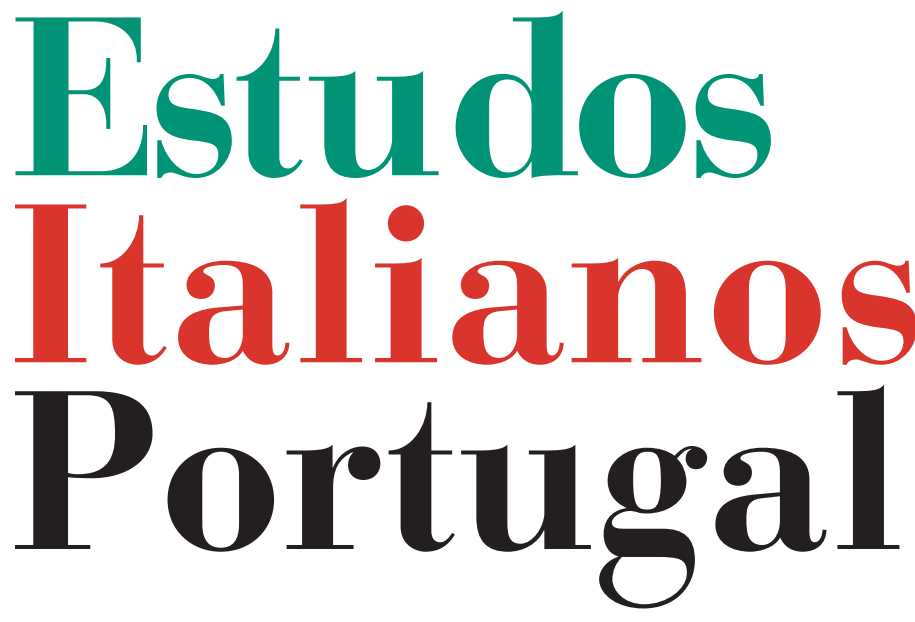

Instituto

Italiano

de Cultura

de Lisboa

Nova Série

$\mathrm{N}^{\mathbf{0}} 13$

2018 
LISBOA E LAGOS NOS SÉCULOS XV-XVI:

A COMUNIDADE ITALIANA E A IGREJA DE NOSSA SENHORA DO LORETO

José António Martins *

\section{INTRODUÇĀO}

Durante o período dos Descobrimentos Portugueses, isto é, entre os séculos XV e XVI, Portugal teve uma maior interligação entre portugueses e comunidades estrangeiras, nomeadamente com os italianos, estando associadas a várias atividades nomeadamente marítimas e económicas, onde o conhecimento de outras áreas e culturas oferecidas pelos Descobrimentos Portugueses, tornaram Lisboa a capital do mundo de então.

Neste âmbito são conhecidas as atividades dos italianos que, entre 1518 e 1523, fundaram na cidade de Lisboa uma igreja, tendo como patrono Nossa Senhora do Loreto. Também o Reino do Algarve conheceu esse desenvolvimento socioeconómico e vilas, como Albufeira, Castro Marim, Faro, Tavira e Lagos, através dos seus portos, exportavam milhares de arrobas de atum salgado de peixe para os principais portos da Europa, destacando-se como mediadores desse comércio de exportação, Milaneses, Genoveses, Sicilianos e Venezianos, muitos dos quais usufruíram vários privilégios, tanto no reinado de D. Manuel I como no de D. João III.

Muitas dessas comunidades de italianos, atendendo ao comércio de exportação, estabeleceram-se na área mais a sul do

* Mestre em História Medieval pela Faculdade de Letra do Porto. Investigador e Técnico Superior de História na Câmara Municipal de Lagos. jajum2010@gmail.com. 
País, destacando-se a vila de Lagos onde, na primeira década do século XVI, se fundou um Convento em honra de Nossa Senhora do Loreto e que para tal teve a intervenção do bispo do Algarve, D. Fernando Coutinho (1502-1538). Atendendo às condições do local da edificação deste Convento, foi o mesmo reedificado em 1560, sendo bispo do Algarve, D. João de Melo e Castro (1549-1564) em outro local, no reinado de D. Sebastião, sendo regente do Reino, D. Catarina de Áustria. Através do estudo da presença dos italianos no Algarve, desde o período da presença do Infante D. Henrique na região até à edificação do Convento de Nossa Senhora do Loreto, tentaremos dar a conhecer a edificação daquele Convento em Lagos, constituindo o mesmo um ponto de encontro espiritual, religioso e cultural entre as comunidades italianas sediadas nesta região algarvia.

\section{O Algarve, Lagos e os italianos}

As relações do antigo Reino do Algarve com comunidades estrangeiras datam de muito cedo e no que concerne com as dos italianos (quer fossem Genoveses, Milaneses, Venezianos, etc.), temos notícia para o século XV, por exemplo, de uma plantação da cana do açúcar em Quarteira, no ano de 1404 por carta de D. João I (Iria 1956: pp. 293-294, 356 e 383).

Contudo, será através do comércio do pescado (proveniente das almadravas) que a incidência das relaçóes do Algarve com os italianos foram fortemente predominantes. No reinado de D. Manuel I, no ano de 1505, o comércio do pescado proveniente das almadravas, tanto do atum como das corvinas, teve um grande incremento na zona de Lagos, destacando-se nesse comercio Bartolomeu "frolemtim" (Iria, id., ibidem) o qual deteve alguns privilégios para a comercialização e exportação de peixe para diversos locais da Europa. A intervenção de estrangeiros na região, através de contra- 
tos, tornou o negócio do peixe uma fonte de rendimentos para os intervenientes, tornando-se numa atividade apetecível para várias comunidades estrangeiras, nomeadamente os italianos.

No ano de 1491 as vilas de Lagos, Tavira, Faro e a cidade de Silves, com os seus almoxarifados, tinham de rendimento das suas almadravas "(...) um conto, duzentos e setenta mil novecentos e sessenta e oito reaes (...)" (Lobo 1981: p. 39).

Os principais detentores desse comércio lucrativo estavam centrados nas comunidades de genoveses, milaneses, sicilianos e venezianos. No que concerne a esta última comunidade - os venezianos - apontamos as relações da vila de Lagos com Veneza, sobejamente conhecidas ao nível das referências documentais (Iria ib.). Os venezianos aportaram às costas da vila medieval de Lagos tendo como intuito tanto o comércio da baleia, na povoação da Luz-Lagos, como o reabastecimento das suas embarcaçóes, fazendo para tal "aguada" em Lagos (Martins 2008: p. 19). Embora a sua presença seja já documentada na primeira década do século XIV, através do “(...) tráfego veneziano de pimenta, servindo as galés da Alta Itália como estação de aprovisionamento no caminho para a Flandres (...)" (Iria ib.), foi com o Infante D. Henrique que as relações comerciais e institucionais (o primeiro consulado veneziano no Algarve estabeleceu-se em Lagos) foram incrementadas (Martins 2002: pp. 44-51) e mantidas pelo menos até ao reinado de D. João II, sendo os habitantes de Lagos detentores de privilégios em relação ao comércio com os venezianos, nomeadamente os relativos à isenção de metade do pagamento da sisa do que comprassem ou vendessem aos venezianos. Podemos pois concluir que a importância deste comércio sediado nas comunidades italianas foi muito importante, onde uma estrutura operacional de captura, conservação e exportação para a Europa, em grande parte, estava sob o domínio de estrangeiros. Comunidades estrangeiras que no Algarve tinham o modus operandi do comércio 
das almadravas, mas também tinham os seus locais de culto, de encontro social e religioso.

\section{A igreja de Nossa Senhora do Loreto, em Lagos}

Se Lisboa, a capital do Reino, era o centro da atividade politica e socioeconómica, não menos importante seria o Reino do Algarve e as suas principais localidades, na confluência de gente de toda a Europa à procura de oportunidades de negócio e de fortuna, tentando estabelecer laços familiares com vista à sua permanência na região, assim como por todo o Reino (Henriques; Margarido 1989: pp. 29-50). Com a permanência mais assídua destas comunidades, tornou-se necessário encontrar meios de residência e de culto nas áreas onde tinham implementado os seus negócios.

A vila de Lagos é um caso interessante, uma vez que nesta vila portuária se edificou uma igreja dita dos italianos, como já tinha acontecido primeiramente em Lisboa, designada como igreja de Nossa Senhora do Loreto. Se a de Lisboa foi construída entre 1518 e 1523, (Filippi 2013: p. 7) (Fig. 1) a de Lagos é descrita como tendo sido fundada no ano de 1518 (Paula 1992: p. 302), sendo bispo do Algarve, D. Fernando Coutinho (1502-1538). Porém questões relacionadas com as condições de insalubridade do terreno e desavenças com a Câmara Municipal local, fizeram com que este convento dedicado a Nossa Senhora do Loreto tivesse pouco tempo de existência, sobretudo relacionado com a sua padroeira. A edificação da igreja de Nossa Senhora do Loreto na vila de Lagos foi efectuada fora do muralhado da vila, e tinha que ter, para a sua sustentabilidade, água proveniente de nascentes ou de poços existentes nas proximidades. A sua construção deveria ser, portanto, num local com água, para a vivência dos seus residentes. Pouco tempo depois da sua edificação, verificouse que o local era prejudicial para a saúde e para estadia per- 
manente. Sabemos que o edifício foi reedificado num área mais acima da construção inicial e que em 1560 ficou na posse dos Franciscanos.

Eis a seguinte questão: se o convento de Nossa Senhora do Loreto foi edificado em 1518 e se no mesmo local se encontrava edificado um convento dos Franciscanos, como explicar o abandono do convento e meio século depois ter passado para a Ordem dos Franciscanos?

Para chegarmos a alguma conclusão, temos que ter presente de um outro facto histórico ocorrido em Lagos e que apenas em 1521 parece ter tido resolução.

$\mathrm{Na}$ verdade, durante o tempo da existência do convento de Nossa Senhora do Loreto surgiram problemas de insalubridade no local edificado e o templo foi abandonado. As comunidades de italianos em Lagos detinham outros espaços de culto e é bem provável que em 1542 com a construção da igreja de São Roque (Paula 1992: p. 359), por milaneses e sicilianos, na zona do areal da Meia-Praia (Lagos) e em 1553 com a edificação da igreja de Nossa Senhora do Porto Salvo, por genoveses, junto à entrada da vila (Rossio da Trindade), passagem de embarcações de ida e volta para Lisboa, ilhas, etc., estes templos ofereceriam, sem dúvida, outras condiçôes para a vivência destas comunidades italianas. Não esqueçamos que já haveria uma Fonte dita das "oito bicas" (Martins 2008, id) e o problema da insalubridade inicial teria terminado. $\mathrm{O}$ problema da água e o acesso da população da vila ao convento, as desavenças entre a Câmara Municipal e os Franciscanos (estes não permitiam o acesso da população no convento para recolha de água) e a construção de um "Cano" dentro da vila (Martins 2008: pp. 21-24), constituíam uma série de condiçóes para que as comunidades italianas pudessem ter o seu templo de culto, de reunião e de sociabilidade, com práticas associadas às suas comunidades.

Em termos de temporalidade, de existência de uma comunidade religiosa no convento de Nossa Senhora do Loreto, 
pensamos que a mesma teve pouco tempo de permanência no primeiro local de edificação do edifício religioso. A reedificação de um novo edifício, com culto para os Franciscanos, em 1560, prova que estes se sobrepuseram à comunidade inicial e não seriam mais incomodados pelas populações e pela Câmara Municipal, no que respeitava ao consumo de água. Doravante e reinado D. Sebastião, tendo como regente do Reino D. Catarina da Áustria, os Franciscanos voltariam a ter um novo espaço religioso e os italianos (nas diversas comunidades sediadas na vila de Lagos) encontrar-se-iam num novo templo construído, tanto por razões socioeconómicas como religiosas.

Até aos anos 20 do século passado (Fig.2), ainda era possível observar algumas das suas estruturas, mas atualmente nada existe que possa identificar o convento de Nossa Senhora do Loreto, posteriormente denominado como Convento de São Francisco, Convento dos Capuchos e Convento de Nossa Senhora da Glória, estando localizado (em parte) o quartel da Guarda Nacional Republica e anteriormente o edifício prisional da cidade.

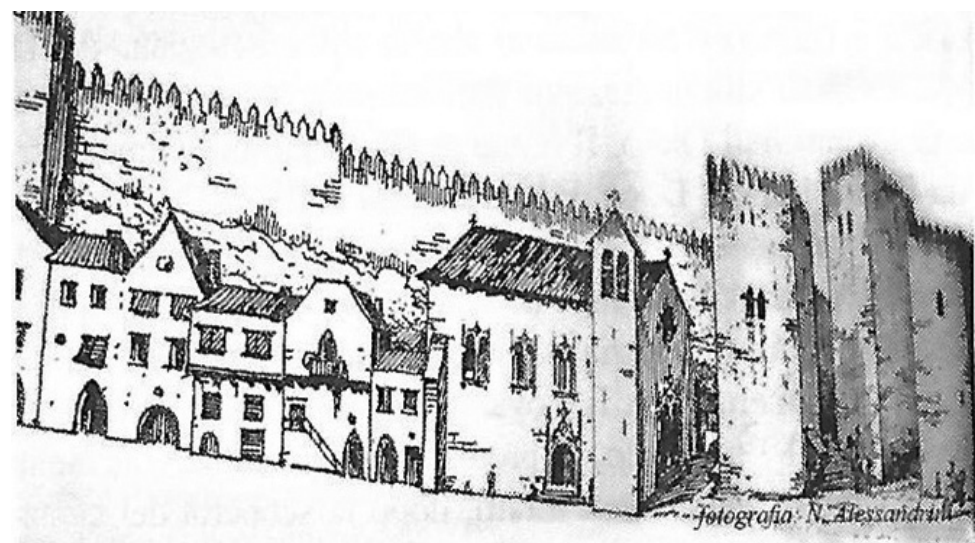

Fig.1 Lisboa - Igreja de Nossa Senhora do Loreto (séc. XVI). 


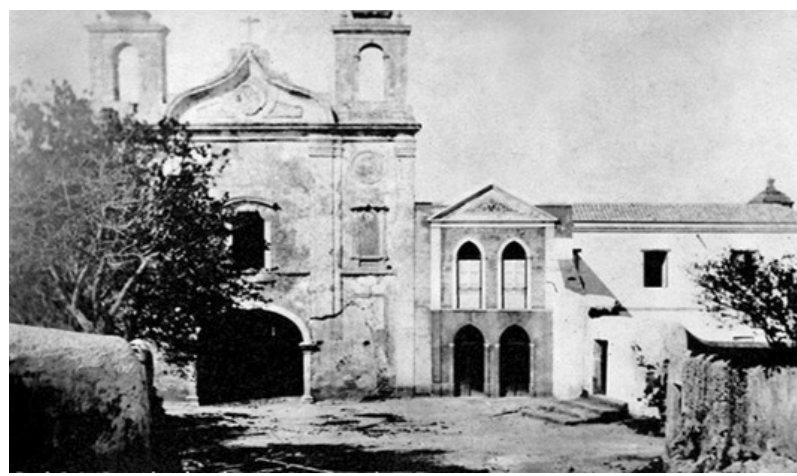

Fig. 2 Lagos - Igreja de Nossa Senhora do Loreto (Anos 20 do séc. XX)

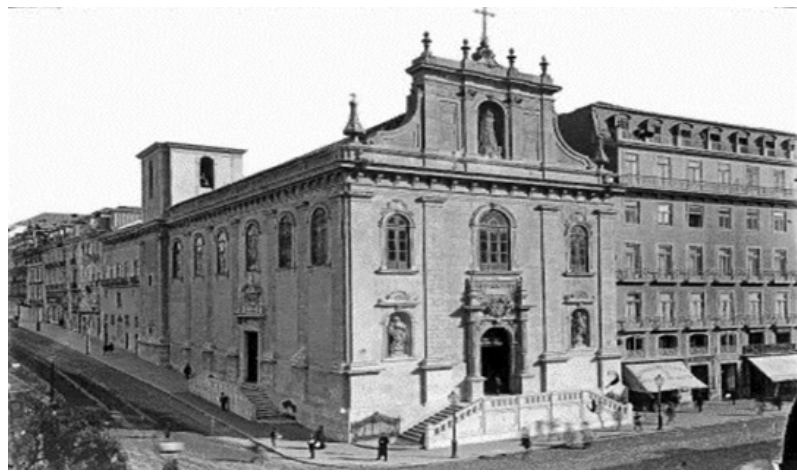

Fig. 3 Lisboa - Igreja de Nossa Senhora do Loreto (anterior a 1895).

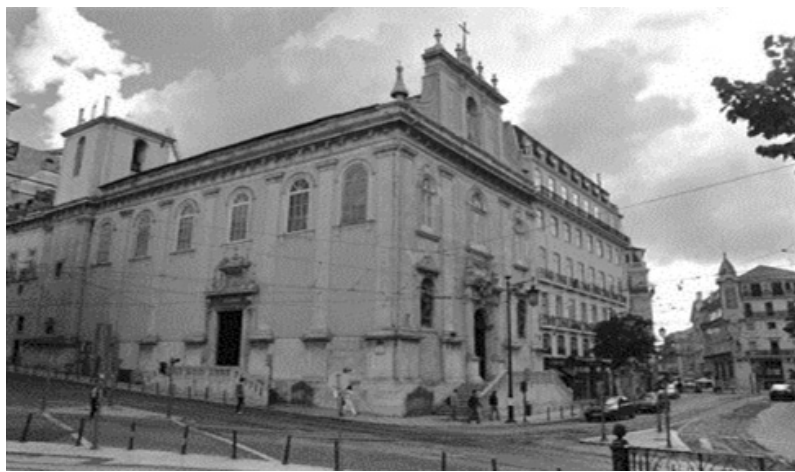

Fig.4 Lisboa - Igreja de Nossa Senhora do Loreto (atualidade). 


\section{BiBLIOGRAFIA}

Alessandrini, Nunziatella; Russo, Mariagrazia; Sabatini, Gaetano; Viola, Antonella (orgs.) (2012), Di buon affetto e commerzio, Relaçôes luso-italianas na Idade Moderna, Lisboa, Centro de História de Além-Mar, Faculdade de Ciências Sociais e Humanas, Universidade Nova de Lisboa, Universidade dos Açores.

Castro, Damião António de Lemos Faria e (1787), Historia geral de Portugal e suas conquistas, Volume VIII, Na Typografia Rollandiana.

Coelho, Maria Helena da Cruz (1995), «A Pesca Fluvial na Economia e Sociedade medieval Portuguesa», Comissão Municipal dos Descobrimentos, VI, Lagos, p. 90.

D’Arienzo, Luisa (1989), "Veneziani in Portogallo e Portoghesi a Venezia nell' etá delle Scoferte", Congresso Internacional Bartolomeu Dias e a Sua Época, Actas, Volume III, Economia e Comércio Marítimo, Universidade do Porto e Comissão Nacional param as Comemoraçóes dos Descobrimentos Portugueses, Porto.

Filippi, Sergio (2013), La Chiesa degli Italiani-Cinque secoli di presenza italiana a Lisbona nell'archivo della Chies adi Nostra Signora di Loreto, Lisboa, Edição Fábrica da Igreja Italiana Nossa Senhora do Loreto.

Henriques, Isabel Castro; Margarido, Alfredo (1989), "Os italianos como revelador do projecto político português nas ilhas atlânticas (séculos XV e XVI)”, Ler História 16 , pp. 29-50.

Iria, Alberto (1956), O Algarve e os Descobrimentos, Vol. II, Tomo I, Lisboa, Edição do Instituto de Alta Cultura.

Lobo, A. de Sousa Silva Costa (1981), História da Sociedade em Portugal no século XV (Prefácio de José Mattoso), Raízes, Lisboa, Edições Rolim.

Lopes, João Baptista da Silva (1988), Corografia ou Memoria Económica, Estadística e Topografica do Reino do Algarve, Lisboa, $1^{\circ}$ Volume, Faro, Algarve em Foco Editora.

Marques, João Martins da Silva (1944), Descobrimentos Portugueses, Vol. I (Documentos para a sua história: 1147-1460), Lisboa, Edição do Instituto para a Alta Cultura, Lisboa.

Marques, João Martins da Silva (1944), Descobrimentos Portugueses, Documentos... Suplemento ao Vol. I (1057-1460), Lisboa, Edição do Instituto para a Alta Cultura.

Martins, José António de Jesus (2002), Lagos Medieval, (Prefácio do Professor Doutor Humberto Baquero Moreno), Edição do Autor.

Martins, José António de Jesus (2008), A Fonte das 8 Bicas, Elementos para a História do Abastecimento de Água à Cidade de Lagos, Junta de Freguesia de S. Sebastião de Lagos.

Oliveira, Julieta Teixeira Marques de (2000), Veneza e Portugal no Século XVI, Subsidios para a sua História, Lisboa, Comissão Nacional para as Comemoraçóes dos Descobrimentos Portugueses, Imprensa Nacional-Casa da Moeda.

Paula, Rui M. (1992), Lagos, Evolução Urbana e Património, Câmara Municipal de Lagos. 